\title{
CLOSED FORMULAE FOR THE STRONG METRIC DIMENSION OF LEXICOGRAPHIC PRODUCT GRAPHS
}

\author{
Dorota Kuziak ${ }^{1}$, Ismael G. Yero ${ }^{2}$ \\ AND \\ JuAN A. RoDRÍGUEZ-VELÁZQUEZ ${ }^{1}$ \\ ${ }^{1}$ Departament d'Enginyeria Informàtica i Matemàtiques \\ Universitat Rovira $i$ Virgili \\ Av. Països Catalans 26, 43007 Tarragona, Spain \\ ${ }^{2}$ Departamento de Matemáticas, Universidad de Cádiz \\ Av. Ramón Puyol s/n, 11202 Algeciras, Spain \\ e-mail: dorota.kuziak@urv.cat \\ ismael.gonzalez@uca.es \\ juanalberto.rodriguez@urv.cat
}

\begin{abstract}
Given a connected graph $G$, a vertex $w \in V(G)$ strongly resolves two vertices $u, v \in V(G)$ if there exists some shortest $u-w$ path containing $v$ or some shortest $v-w$ path containing $u$. A set $S$ of vertices is a strong metric generator for $G$ if every pair of vertices of $G$ is strongly resolved by some vertex of $S$. The smallest cardinality of a strong metric generator for $G$ is called the strong metric dimension of $G$. In this paper we obtain several relationships between the strong metric dimension of the lexicographic product of graphs and the strong metric dimension of its factor graphs.
\end{abstract}

Keywords: strong metric dimension, strong metric basis, strong metric generator, lexicographic product graphs.

2010 Mathematics Subject Classification: 05C12, 05C69, 05 C76.

\section{REFERENCES}

[1] D. Geller and S. Stahl, The chromatic number and other functions of the lexicographic product, J. Combin. Theory Ser. B 19 (1975) 87-95. doi:10.1016/0095-8956(75)90076-3

[2] R. Hammack, W. Imrich and S. Klavžar, Handbook of Product Graphs, 2nd Ed. (CRC Press, Boca Raton, 2011). 
[3] F. Harary and R.A. Melter, On the metric dimension of a graph, Ars Combin. 2 (1976) 191-195.

[4] J. Kratica, V. Kovačević-Vujčić, M. Čangalović and M. Stojanović, Minimal doubly resolving sets and the strong metric dimension of some convex polytopes, Appl. Math. Comput. 218 (2012) 9790-9801.

doi:10.1016/j.amc.2012.03.047

[5] J. Kratica, V. Kovačević-Vujčić and M. Čangalović, Computing strong metric dimension of some special classes of graphs by genetic algorithms, Yugosl. J. Oper. Res. 18 (2008) 143-151. doi:10.2298/YJOR0802143K

[6] J. Kratica, V. Kovačević-Vujčić, M. Čangalović and N. Mladenović, Strong metric dimension: A survey, Yugosl. J. Oper. Res. 24 (2014) 187-198. doi:10.2298/YJOR130520042K

[7] D. Kuziak, I.G. Yero and J.A. Rodríguez-Velázquez, On the strong metric dimension of corona product graphs and join graphs, Discrete Appl. Math. 161 (2013) 1022-1027. doi:10.1016/j.dam.2012.10.009

[8] D. Kuziak, I.G. Yero and J.A. Rodríguez-Velázquez, Strong metric dimension of rooted product graphs, Int. J. Comput. Math. 93 (2016) 1265-1280. doi:10.1080/00207160.2015.1061656

[9] D. Kuziak, I.G. Yero and J.A. Rodríguez-Velázquez, Erratum to "On the strong metric dimension of the strong products of graphs", Open Math. 13 (2015) 209-210. doi:10.1515/math-2015-0020

[10] D. Kuziak, I.G. Yero and J.A. Rodríguez-Velázquez, On the strong metric dimension of the strong products of graphs, Open Math. 13 (2015) 64-74. doi:10.1515/math-2015-0007

[11] T.R. May and O.R. Oellermann, The strong dimension of distance-hereditary graphs, J. Combin. Math. Combin. Comput. 76 (2011) 59-73.

[12] N. Mladenović, J. Kratica, V. Kovačević-Vujčić and M. Cangalović, Variable neighborhood search for the strong metric dimension problem, Electron. Notes Discrete Math. 39 (2012) 51-57. doi:10.1016/j.endm.2012.10.008

[13] O.R. Oellermann and J. Peters-Fransen, The strong metric dimension of graphs and digraphs, Discrete Appl. Math. 155 (2007) 356-364. doi:10.1016/j.dam.2006.06.009

[14] J.A. Rodríguez-Velázquez, I.G. Yero, D. Kuziak and O.R. Oellermann, On the strong metric dimension of Cartesian and direct products of graphs, Discrete Math. 335 (2014) 8-19. doi:10.1016/j.disc.2014.06.023

[15] A. Sebő and E. Tannier, On metric generators of graphs, Math. Oper. Res. 29 (2004) 383-393. doi: $10.1287 /$ moor. 1030.0070 
[16] P.J. Slater, Leaves of trees, Congr. Numer. 14 (1975) 549-559.

[17] E. Yi, On strong metric dimension of graphs and their complements, Acta Math. Sin. (Engl. Ser.) 29 (2013) 1479-1492.

doi:10.1007/s10114-013-2365-z

Received 1 August 2015

Revised 27 January 2016

Accepted 27 January 2016 